\title{
Pre-Primary Education in Jordan: Issues of Access and Participation
}

\author{
Omar Bataineh \\ Assistant Professor \\ Department of Educational Administration \\ College of Educational Sciences \\ Hashemite University, Zarqa, Jordan \\ Ahmad Qablan \\ Associate Professor \\ Department of Curriculum and Instruction \\ College of Educational Sciences \\ Hashemite University, Zarqa, Jordan \\ \& \\ Visiting Professor \\ Department of Elementary Education \\ Faculty of Education \\ University of Alberta \\ Canada
}

\begin{abstract}
Pre-primary education in Jordan is still facing several barriers especially at the time of massive influx of Syrian refuges to the country. This study came to examine the detailed profiles of out-of-school children at pre-primary stage in Jordan in order to highlight the major barriers to school access and participation, analyze existing and emerging education policies and strategies to tackle key bottlenecks; and provide recommendations for improvement to policy makers. Data were collected from several sources utilizing both quantitative and qualitative approaches. Results showed that $41 \%(45,862)$ of pre-primary Jordanian students are currently not enrolled in schools. Additionally, female students seem to be more willing to attend pre-primary schools (59.7\%) comparing to their male counterparts (58.3\%). Several recommendations were offered to enhance the access and participation of pre-primary children in schools such as; establishing more pre-primary centers in urban areas and providing specialized professional development for Pre-primary teachers. (150 words)
\end{abstract}

Keywords: Out of School Children (OOSC), Pre-primary Education, School Enrolment, Jordan

\section{Introduction:}

Several countries across the world suffer from attracting young children to enroll in preprimary and primary education. According to the world data from the UNESCO Institute for Statistics (UIS), 61 million children of primary school age were out of school in 2010 (UIS, 2010). It is also expected that this number will increase due to several problems around the world. Most of those out of school children exist in developing countries. Tackling the problem of Out of School Children (OOSC) has become a global priority. Investing in the early ages of children is essential to overcome the problem. Early childhood is a period of intense advances in reasoning, language acquisition, and problem solving. Therefore, a child's environment can dramatically influence the magnitude of these skills. By supporting development when children are very young, early childhood education programs can complement parental investments and produce large benefits to children, parents, and society at all.

\subsection{The Significance of Early Childhood Education}

A substantial body of research concludes that pre-primary education can improve the learning and development of young children (Cascio, 2010; Dhuey, 2011; Havnes and Mogstad, 2011; Spiess, Büchel, and Wagner, 2003). Several studies have examined the immediate effects of pre-primary education for children during their first five years of life (Berlinksi, Galiani, and Gertler, 2009; Caille, 2001). 
Some have compared the outcomes for pre-primary education against other options: outcomes for a true control group having no pre-primary education; outcomes for typical experience (which includes child care outside the home); and outcomes for more or less well-defined alternatives (for example, outcomes for pre-primary education programs using different curricula) (Cascio, 2009, 2010; Dhuey, 2011).

To measure the impact of this sort of pre-primary education on cognitive development of children, several studieshave utilized a meta-analysis statistical technique. For example, meta-analyses conducted over the past 25 years have found pre-primary education to produce an average immediate effect of about half $(0.50)$ a standard deviation on cognitive development (Gorey, 2001). This is the equivalent of 7 or 8 points on an IQ test.

For the social and emotional domains, estimated effects of pre-primary education have been somewhat smaller but still practically meaningful, averaging about 0.33 standard deviations (Bernal \& Keane, 2011). To put these gains in perspective, it's important to realize that on many measures, a half standard deviation is enough to reduce by half the school readiness gap between children in poverty and the national average (Barnett, Carolan, James, Kristy, 2013).

Several studies have also examined the long term impact of pre-primary education on elementary school and beyond (Aos, Lieb, Mayfield, Miller, Pennucci, 2004). Latest meta-analyses of these studies find that pre-primary education has significant lasting effects on students' cognitive abilities, school progress (grade repetition, special education placement, and high school graduation), and social behaviour (Aos., et.al., 2004). However, the impacts of pre-primary education decline as students move from immediate experience to elementary school, to adolescence, and to adulthood follow-up.

\subsection{The Case of Early Childhood Education in Jordan}

In Jordan, pre-primary education has been introduced to the national education system in 1994. Act no. (3) /1994 emphasized the philosophical, physiological, cognitive and social bases of education, expanded the basic education stage to include the first ten grades and introduced the Kindergarten (KG) stage as a formal but not compulsory stage in the educational ladder, whereas basic education is compulsory and free of charge, secondary education is also free but not compulsory.

Too, the national reform for knowledge economy (ERfKE) program which was initiated in 2002, emphasized the importance of establishing pre-primaryclasses in the country (MoE, 2013). In order to systemize the process of establishing KG classes, the Ministry of education established the National Early Childhood Network regional groups in 2012. The major roles of these groups were to identify needs for Kindergartens (KGs), mobilize support for KGs, coordinate with public/private universities for practical education of students, and lead communication campaigns.

As a result of that, several pre-primaryclasses have been opened across the country. However, ample critiques have been presented to MOE for not enforcing the act and opening more KG classrooms in every school resulting in limiting people to send their children to pre-primary. The purpose of this study is to assess the progress in establishing KG education in Jordan in both government and private sectors and identify the challenges and obstacles that face preprimary education in the country.

\subsection{Research Questions:}

This study aimed to answer the following questions:

1. What is the enrolment rate of students in pre-primary education in Jordan?

2. What is the number of out of school children at the age of KG in the country?

3. What are the challenges that face both $\mathrm{MOE}$ and Jordanian people regarding national pre-primary education programs?

To answer these questions, a recently developed conceptual and methodological framework (CMF) has been used (UNICEF and UIS, 2013). The CMF helps researchers tackle the exclusion problem of OOSCchildren through considering the Five Dimensions of Exclusion stages that capture excluded children from the pre-primary to lower secondary school age across multiple layers and a wide range of disparities and includes various degrees of exposure to education.

\subsection{Conceptual and Methodological Framework (CMF)}

The CMF's Five Dimensions of Exclusion (Figure 1)wasthe guide to conduct the study. The Five Dimensions of Exclusion systematically disaggregate statistics on out-of-school children according to their characteristics, such as wealth, disability, location, gender, race/ethnicity and age group. In addition to that, it looks at the interaction between the disparities that create complex and mutually reinforcing patterns of disadvantage and barriers to schooling. 
Figure 1.The Five Dimensions of Exclusion (UNICEF 2013)

\begin{tabular}{|c|c|c|c|}
\hline Dimension 1 & \multicolumn{3}{|c|}{ Dimension 2 } \\
\hline $\begin{array}{c}\text { Not in pre- } \\
\text { primary or } \\
\text { primary } \\
\text { school }\end{array}$ & $\begin{array}{c}\text { Attended } \\
\text { but } \\
\text { dropped } \\
\text { out }\end{array}$ & $\begin{array}{c}\text { Unlikely to } \\
\text { ever enter }\end{array}$ & $\begin{array}{c}\text { Likely to } \\
\text { enter } \\
\text { school in } \\
\text { the future }\end{array}$ \\
\hline $\begin{array}{c}\text { Pre-primary } \\
\text { age children }\end{array}$ & \multicolumn{3}{|c|}{ Primary age children } \\
\hline
\end{tabular}

\begin{tabular}{|c|c|c|}
\hline \multicolumn{3}{|c|}{ Dimension 3 } \\
\hline $\begin{array}{c}\text { Attended but } \\
\text { dropped out }\end{array}$ & $\begin{array}{c}\text { Unlikely to } \\
\text { ever enter }\end{array}$ & $\begin{array}{c}\text { Likely to } \\
\text { enter } \\
\text { school in } \\
\text { the future }\end{array}$ \\
\hline
\end{tabular}

Out of school

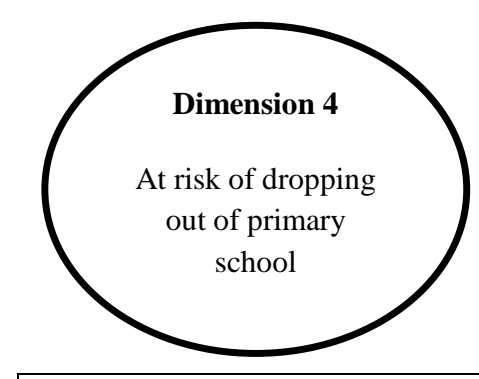

Lower secondary age children

Primary school students

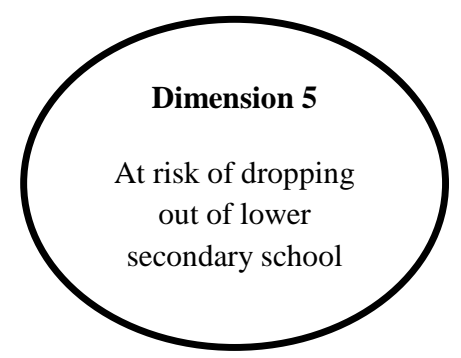

In

school

In general, children of pre-primary, primary, or lower secondary school age are considered as being in school if they participate in primary or secondary education. Children of pre-primary, primary, or lower secondary age who do not participate in education programs are considered to be out of school (Dimensions 1, 2 and 3). Children currently in school but at risk of dropping out from either primary or lower secondary school are captured in Dimensions 4 and 5 of the framework. According to Lewin (2007), understanding more about these groups of children is crucial to preventing them from becoming the out-of-schoolchildren of tomorrow.

The utilization of the Five Dimensions of Exclusion framework issuitable for the purpose of this study as it helps identify the rate of enrolment at the pre-primary education level and identify the profiles of excluded children, barriers and bottlenecks related to their exclusion, and the policies and strategies to address the barriers.

\section{Methodology}

Both quantitative and qualitative research techniques were used to collect data for this study (Bogdan \& Biklen, 1998; Glesne, 1999). The rationale of employing the mixed methodology of data collection is that relying only on quantitative data might not provide insight into the barriers, bottlenecks, and policies that encourage children to be out of school. The most thorough types of research methodology use data gathered in a variety of ways, including interviews, observations, and surveys (Babbie, 2005).

The study employed several data sources such as; Administrative and household survey (DHS) data, Educational Management Information System (EMIS) data, and the Department of Statistics (DOS) database. However, several national reports and information that were published by several ministries in Jordan were utilized to extract the needed statistical figures regarding out-of-school children.

In addition to the quantitative data, the study gathered several types of qualitative data and employed more than one set of tools (Annex 1) for data collection and analysis such as:

- Key informant interviews.

- Focus group interview of teachers, out-of-school children, supervisors and parents.

Each of the interview instruments was designed in a generic format that permitted the interviewer to 'customize' and adjust the questions to help explore the barriers, bottlenecks and the policy issues that encourage children to be out of school.

\subsection{Participants Selection}

The educational services that the MoE provides cover all regions in the country. However, the issues that face out-ofschool children differ from region to region.

Therefore, quantitative figures drawn from EMIS database was used to identify the areas across the country that showed high rates of outof school children. The qualitative research then targeted participants from identified regions to get a better representation and understanding of the nature of issues and barriers that out-of-school children face. 
In addition, the study includes multiple insights and perspectives from different people when conducting interviews and focus groups. For example, focus groups consisted of several types of participants such as parents, children and education supervisors.

\subsection{Data analysis}

Quantitative data were tabulated, and comparisons were made between different statistical information and databases with the qualitative data collected. It is important to note that the researchers faced several obstacles while trying to collect the needed quantitative data. One of these obstacles is the old national population estimate (2002) that is available from the Department of Statistics (DOS). This estimate does not give an accurate picture of out ofschool children in the country. This obstacle has become more pronounced due to the massive influx of refugees to the country and the consequences that it has on the quality of education and the learning environment in the classrooms.

For analyzing qualitative data, each interview and/or focus group transcript was analyzed in three major stages: open coding, selected emergent themes and focused coding (Emerson, Fretz\& Shaw, 1995). In open coding, each transcript was read line-byline to identify and formulate all ideas, barriers (bottlenecks) or issues they suggested, no matter how varied and disparate. In the focused coding, data were subjected to fine-grained, line-by-line analysis on the basis of bottlenecks that were identified as being of particular interest from the open-coding analysis. In this stage, coded data were then combined under major themes (Bogdan \& Biklen, 1998) and organized into broad categories based on the Five Dimensions of Exclusion. By doing this, the researchers were able to identify the sort of barriers, bottlenecks and policies that face out-of-school children.

\section{Results:}

The total number of in-school children at the pre-primary level (4-5 years old) is about $(111,771)$, with the total number of girls $(53,363)$ being lower than the number of boys $(58,408)$ (Table 1$)$.

Table 1.Number of in-school children in Kindergarten 1 \& 2 (KG 1\& KG 2) (ages 4-5 years old), by gender Girls

Boys Total

\begin{tabular}{rrrrrr} 
& KG 1 & \multicolumn{1}{c}{ KG 2 } & \multicolumn{1}{c}{ KG 1 } & \multicolumn{1}{c}{ KG 2 } & \\
4 years & 11,313 & 100 & 13,767 & 155 & 25,335 \\
5 years & 1,027 & 40,923 & 201 & 44,285 & 86,436
\end{tabular}

As shown in the table above, $41 \%$ of KG 2 age children are not in school. The total number of out of school children is 45862,21541 of them are girls, while the rest are boys. The percentage of Jordanian out-of-school children in preprimary level seems to be a serious problem, with a significant increase during the past five years. Around $41.0 \%$ $(60,175)$ of the children who are at the KG 2 age are out of school. Trends in Net Enrolments Rate(NER) in both KG 1 and 2 over years indicate that it has been stable since 2004, with a slight increase from 31.6 to $38 \%$ in 2013 (see Figure.2). The NER for KG 1 is still very low (below $20 \%$ ) for both genders, while it is around $56 \%$ for children in KG 2.

Figure 2. NER in KG 1 and 2, by year

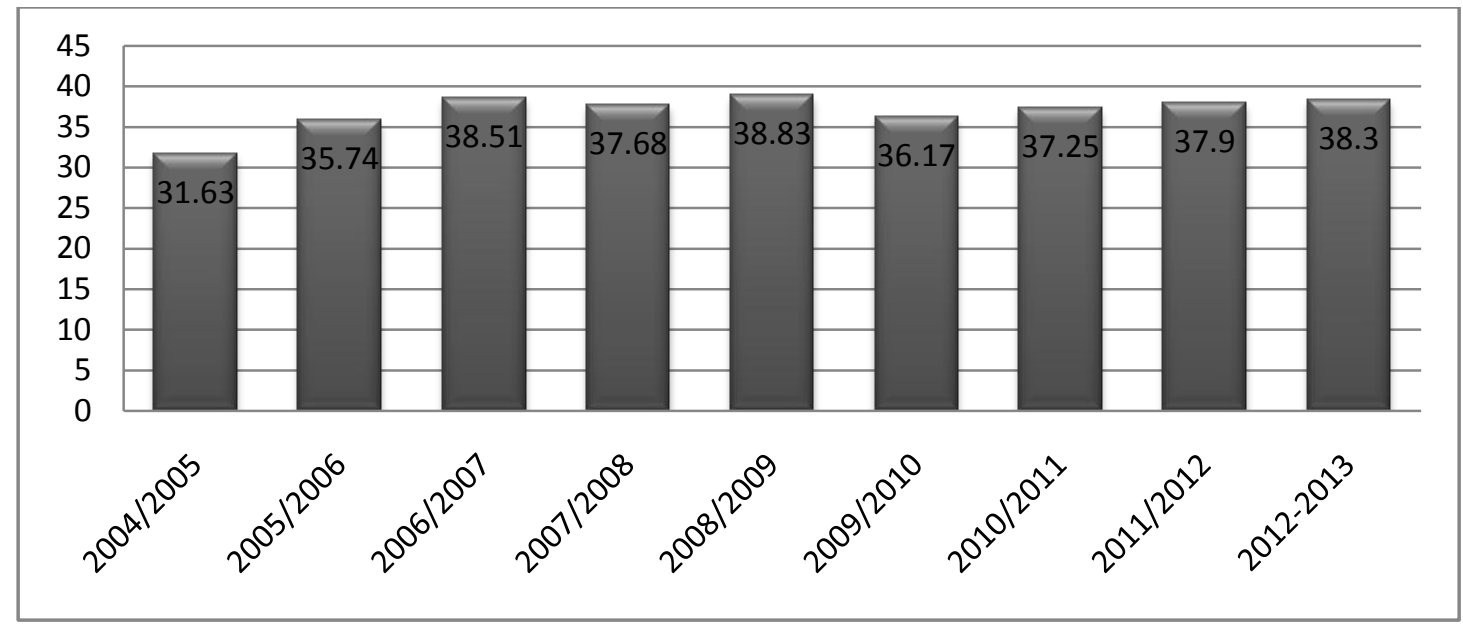


The highest enrolment rates in KG 1 and 2 are in major cities (Amman, Irbid, Zarqa and Balqa). The capital city of Amman had the highest enrolment number for KG $1(12,000)$ and for KG $2(30,000)$, followed by the second biggest city in the country, Irbid, where the number of enrolled children in KG 1 is 3,600 and in KG 2 is 15,000.

A possible reason for this finding is private sector investment in establishing $\mathrm{KG}$ schools in these major cities. However, private-sector investment in other small cities is restricted by the low population numbers and the lack of availability of $\mathrm{KG}$ in public schools.

In addition to the private sector, there are three other authorities that offer KG schooling in Jordan. The enrolment rate of different grade levels is distributed by authority. Almost all KG 1 enrolment is managed by the private sector; while KG 2 enrolment is shared between three education authorities: MoE, private sector and non-MoE schools, such as school of the Ministry of Social Affairs (see Figure 3).

Figure 3. Student percentages by authority and grade level, 2012

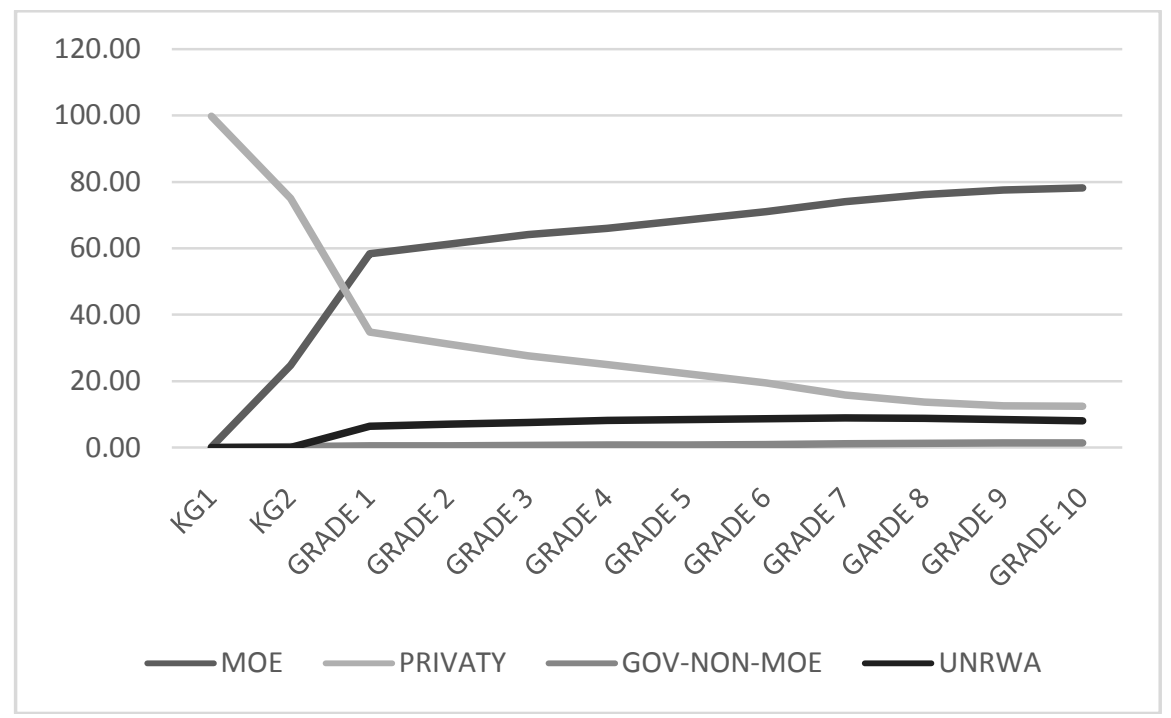

The gender parity index (GPI) for the NER at the pre-primary school level is 0.971 . The lack of pre-primary education is a major cause for low enrolment at the pre-primary level. In recent years, there has been a significant growth of private and community based pre-primary institutions, which helped meet the demand. Also, there is an increasing interest from MoE to consider KG as a formal education stage in the national education system. Annex 2 shows the number of enrolled KGchildren and sections, and their distribution among different governorates and educational authorities across the country.

In addition to the lack of school facilities suitable for KG children, there are several other barriers that contribute in reducing the enrolment rate at this level.

To obtain an overview of early childhood education (ECE) indicators in Jordan, data from the Jordan Population and Family Health Survey (JPFHS) (2013) was used. According to data from this survey, $22 \%$ of children aged 3 to 5 years are attending an organized ECE program. Children aged 4 to 5 years are three and a half times more likely to attend an organized ECE program as children age 3 to 4 years (35\% versus $10 \%$ ). Female children are slightly more likely to be engaged in ECE programs than male children. Urban children are slightly more likely to be in ECE programs than rural children. Children living in the North region are most likely to attend ECE programs. The percentage of children attending ECE programs ranges from a low of $17 \%$ in Mafraq and Zarqa to a high of $29 \%$ in Irbid. ECE program attendance is also higher in the non-Badia and non-camp areas of Jordan. Attendance at ECE programs varies positively with mothers' education and household wealth.

Barriers to ECE require serious attention from all involved stakeholders. The neglect in resolving these barriers will result in significant increases in the number of out of school children at the KG level. The number of out-of-school children at the KG level is project to increase if the current trend and enrolment restrictions continue (see Figure 4). 
Figure 4. Projection of out-of-school children at KG level (ages 4-5), 2012-2020

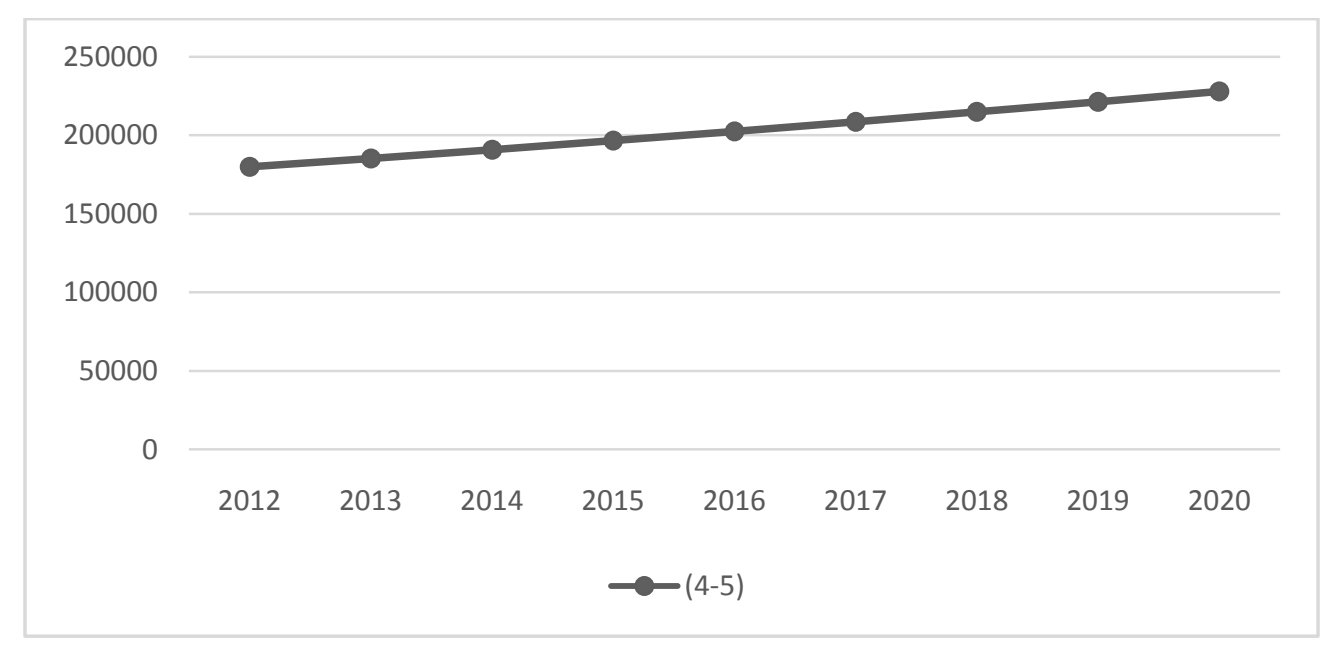

\subsection{Children entering school without pre-primary experience}

The pre-primary enrolment rate in Jordan is low. Only $58 \%$ of children entering primary school have pre-primary experience. This low rate has been attributed to several factors such as the lack of KG facilities in public schools, high school fees and other indirect costs. However, the MoE is currently working hard to overcome these barriers through its comprehensive educational reform project (ERfKE II). The MoEhas studied several options for KG expansion that include; creating KG sections in existing primary and secondary schools, using space available at many underutilized schools; and piloting double-shifts in schools that are not already double-shift.

\section{Discussion, Conclusions and Ways Forward}

The MoE has a growing interest in pre-primary education, which is one of the five main components of ERfKE II, and is committed to improving the capacity of MoEfor KG levels. According to the 2013 ERfKEII Annual Narrative Report, the MoE dedicated a special component of its national educational reform project to improving inclusive access to learning for all children through a special focus on three critical subsectors: Early Childhood Education (ECE), Special Education and Vocational Education (MoE, 2013). The MoE has also identified the following four major policies for ECE through its newPolicy Framework for Early Childhood Education component:

1. The MoE shall consider the pre-primary stage as part of formal education, but not compulsory education.

2. The MoE shall establish KGs within its capabilities according to a staged plan.

3. The MoE shall provide a suitable environment to create a well-balanced education for children.

4. The MoE shall increase the KG budget within the MoE budget.

As indicated in the Annual Narrative Report (2013), the MoEwill continue to partner with private providers in order to ensure the implementation of the policy options scenarios for KG expansion by: Creating KG sections in existing primary and secondary schools, using space available at many underutilized schools, further piloting of double-shift in schools that already use double-shift schooling. However, even with significant change, the enrolment rate of preprimary age children into the education system is still low (38\%). There are several barriers that account for the low rate, some relate to the enabling environment while others relate to the supply side. These barriers are analyzed based on the two categories of exclusion; enabling environment and supply and demand.

\subsection{Enabling Environment Barriers}

Although some parents are willing to send their children to KG, others are not. Parents' unwillingness was attributed to their lack of awareness of the importance of KG education to their children's future. However, those parents who are willing to send their children to KG often encounter social and economic barriers that may include the nature of their family work, which requires them to seasonally migrate from place to place seeking food and water for their livestock (NCFA, 2012).

Other critical community-related barriers are families' social conditions, such as the high divorce rate that dominates some communities, as evident in all focus groups, which in turn results in disintegrated families and a family atmosphere that makes it difficult to plan for the future of their children.

"My father and mother are divorced. I live with my mother. I didn't go to KG because my mother goes to work, and I stay at home with my little sisters and brothers." (Girl from Der Alla) 
The data also show that some families think that their children are too young to be sent out alone to KG, where they might be exposed to the unsafe roads and unsafe school environments.

"I don't send my little kids to KG because the school is away from my home and I am afraid to send them alone to walk a long distance to school every day."

(Mother from Jezza)

Children with disabilities at the KG level face a number of barriers. As mentioned in their interviews, there are several reasons that discourage them from enrolling in KG. Most of these children are excited to learn but finding specialized centers or help to accurately diagnose their type of the disability is challenging. It is difficult within the education system for children with disabilities to find a school to attend.

"My little son has a learning disability and I don't send him to school because putting him in regular classroom would not help him learn." (Mother from Ramtha)

\subsection{Supply-Related Barriers}

In addition to the environment-related barriers, there are also supply-related barriers that interfere with pre-primary school enrolment. Almost all interviewees commented on several MoE policies that regulate KG schools. They critiqued the policy that limits the maximum number of students in KG classrooms; they argued that limiting the maximum classroom capacity to 25 children per classroom does not give equal opportunities to all children in the region. In addition to that, some critiqued the termination of school health programs in pre-primary, which was very supportive and encouraging to their children.

"There is only one KG section in our village school, and according to the MoEpolicy, they don't accept above 25 children in this section." (Mother in Southern Badia)

The cost associated with sending their children to KG was another critical supply-related barrier that parents encounter. Recent statistics of MoE - EMIS database shows that the total number of KGs in the country is 6,090, but only 1,060 are owned by the MoE (EMIS, 2013). Such a limited number of free KGs makes it hard for poorer families to find a place for their children, especially when the MoElimits the maximum capacity of KG classrooms to 25 students. However, if the KG has available spaces but is far away from home, parents decide against sending their young children to school due to the expense of transportation and the dangers of their children to walking to school alone.

In addition to that, most parents believe that the available KG classrooms are insufficiently furnished, limited in capacity, and that the teachers are not well prepared to teach KG.

However, among all these barriers, the economic barrier seems to be the most pressing factor that reduces the enrolment rate in pre-primary stage.

"I would love to send my child to a KG school, but the school is located far away from my home and I don't have the financial capability to send them by bus."

(Mother from Jezza)

Most parents are overwhelmed with their financial responsibilities to the degree that they cannot afford paying fees to send their children to pre-primary. This barrier has become even more pressing during the current economic downturn in Jordan. With respect to children with disabilities, the lack of technical capacity to diagnose the type and severity of disability seems to be a serious barrier that reduces their enrolment in KG schools. However, in cases where they found a diagnosis, children with disabilities face a supply barrier of finding a suitable school that deals with their disability. The problem is further complicated when several types of disability are identified.

In addition, some parents complained about the weak management and coordination between MoE and parents, as well as between MoEand other government ministries such as the Ministry of Social Affairs. This lack of coordination results in reduced rates of school enrolment among children with disabilities.

\subsection{Overcoming the Barriers}

Enrolment in pre-primary is still very low, but important steps have been taken to enhance that rate. Several studies emphasize the importance of investing in children from a very young age, as the early years of a child's life are of crucial importance for future development (Cascio, 2010; Dhuey, 2011; Havnes and Mogstad, 2011; Spiess, et.al., 2003). The significant, positive role of high-quality early childhood programs in cognitive development is well established and the impact has been found to be greater for younger children ( 2 to 3 years old) (Gorey, 2001). Studies also emphasize that investing in quality pre-primary education is the most cost-effective period to invest in with respect to both cognitive and non-cognitive benefits and future economic returns, and becomes less cost-effective with increasing age (Heckman, 2006). Early intervention can also reduce future disparities in achievement between pupils of both genders and those of different socio-economic levels. 
The significance of improving pre-primary enrolment is furthered as studies have shown that children without any preprimary experience are at a higher risk of dropping out and on average do not do as well at school (OECD, 2013).

However, to enhance the enrolment rate and quality of pre-primary education in Jordan, the ministry of education needs to increase the compulsory years of schooling in the national education system by adding KG $1 \& 2$ stages. Regardless of the high, pre-primary education will have a significant impact, at a later stage, on the national economy. Too, making both KG 1 and 2 education compulsory, will encourage parents to send their children to pre-primary and advance their skills and readiness to primary education. It is also important that the MoE targets areas that have large number of KG aged children in order to reach the maximum number of children.

Providing specialized professional development programs for pre-primary teachers is another important point that the MoE needs to consider. According to some interviewee parents, they complained of the poor preparation of preprimary teachers. In order to accommodate the diverse needs of KG students, teachers need to receive intensive and continuous professional development to help them attract children to schools as accommodating students' needs at this critical stage would significantly contribute to enhance their achievement in the upper grades.

In the same vein, expanding the "Better Parenting Program" to educate parents on proper rearing practices and encouraging them to send their children to $\mathrm{KG}$ is essential to enhance their children readiness to enter pre-primary and maximize their learning. Launching national awareness campaigns to raise people's awareness of the importance of KG education seems to be an excellent option, especially after making the pre-primary education compulsory.

Similarly, strengthening the communication between schools and parents is important to maximize children learning during pre-primary stage. There are several suggested modes of communication that can be utilized such as mosques, media, radio, social media, school websites, etc.

\section{References}

Aos, S., Lieb, R., Mayfield, J., Miller, M., \&Penuchi, A. (2004). Benefits and costs of prevention and early intervention programs for youth, Olympia, WA: Washington State Institute for PublicPolicy.

Babbie, E. (2005). The practice of social research,Belmont, California: Wadsworth.

Barnett, W. Steven, Megan E. Carolan, James H. Squires, Kristy C. Brown. (2013). The State of Preschool, National Institute for Early Education Research.

Bernal, R., and Keane, M. (2011). Child Care Choices and Children's Cognitive Achievement: The Case of Single Mothers, Journal of Labor Economics, 29(3), 459- 512.

Bogdan, R. C., \& Biklen, S. K. (1998). Qualitative research for education: An introduction to theory and methods (3ed Ed.). Needham Heights, MA: Allyn\& Bacon.

Cascio, Elizabeth. (2009). Do investments in universal early education pay off? Long-term effects of introducing KGinto public schools, NBER Working Paper 14951.

Cascio, Elizabeth. (2010). What happened when KG went universal?Education Next, 10(2), 62-69.

Dhuey, Elizabeth. (2011). Who benefits from KG? Evidence from the introduction of state subsidization,Education Evaluation and Policy Analysis, 33(1).Department of Statistics. (2013). Retrieved in November 26, 2015 from:http://www.dos.gov.jo/dos_home_e/main/

Emerson, R. M., Fretz, R. I., \& Shaw, L. L. (1995). Writing ethnographic fieldnotes, Chicago: University of Chicago Press.

Glesne, C. (1999). Becoming qualitative researchers: an introduction, 2ed edition.

Addison Wesley Longman, Inc., NY.

Gorey, K. M. (2001). Early childhood education: A meta-analytic affirmation of the short- and long-term benefits of educational opportunity, School Psychology Quarterly,16(1), 9-30.

Havnes, Tarjei and Mogstad, Magne. (2011). No child left behind: Subsidized child care and children's long-run outcomes, American Economic Journal: Economic Policy, 94(5), 1613- 1634.

Lewin, K.M. (2007). Improving Access, Equity and Transitions in Education: Creating a Research Agenda, CREATE Pathways to Access Series, Brighton: University of Sussex.

Ministry of Education (MoE). (2013). Education Reform for Knowledge Economy second phase (ERfKE II), Annual Narrative Report.

Spiess, C. Katharina, Büchel, Felix and Wagner, Gert G. (2003). Children's school placement in Germany: does KG attendance matter? Early Childhood Research Quarterly, 18(2), 255-270.

UNICEF and UIS. (2011). Global Initiative on Out-of-School Children: Conceptual and Methodological Framework (CMF), New York.

UNESCO Institute for Statistics. (2010). Global Education Digest: Comparing Education Statistics across the World, Montreal, Canada. 


\section{ANNEXES}

\subsection{ANNEX 1.}

\section{Key Informant \& Focus Group Interview Guide}

This interview instrument is for collecting information from multiple key informed people. Some of the questions below should be modified, expanded or eliminated depending on the particular individual or group of respondents.

Interviewer:

Date: 2013

PART 1: RESPONDENT BACKGROUND INFORMATION

\begin{tabular}{|l|l|}
\hline $\begin{array}{l}\text { For Individual Interview: } \\
\text { Respondent Name: } \\
\mathrm{M} / \mathrm{F}\end{array}$ & Title/Function: \\
\hline For Focus Group: & Positions: \\
Number:__ F +_ Male $=\ldots$ Total & \\
\hline Organization/School/Directorate: & Contact/Location Info: \\
\hline Other observations about respondent: & \\
\hline
\end{tabular}

PART 2: Key Informant Questions

\section{Questions for MoE Officials}

1. Please describe, from your experience, the reasons (Educational regulations, economic, social, Familial, educational) that discourage people from sending their children to PPE School?

2. Please describe, from your experience, the reasons (Educational regulations, economic, social, Familial, educational) that discourage people from sending their children to PE School?

3. Please describe, from your experience, the reasons (Educational regulations, economic, social, familial, educational) that encourage/discourage children to drop out from the school?

4. Other comments or solutions?

Questions for Parents

Age: Gender: Region: Job: Health:

1. Do you send your Children to PPS? Why and Why not?

2. Do you have any child who did not enter the primary school? Yes No

If Yes: Please describe the reasons that prevent him/her from entering the school.

Points for the interviewer: (Educational regulation, economic, social, familial, educational...).

3. Do you have any child who dropped out of the school? Yes No

If Yes: Please describe the reasons that encourage him/her to drop out of school?

Points for the interviewer: (Educational regulations, economic, social, familial, educational...).

4. Other comments or solution? Questions for School Age Children (Not Enrolled)

Age: Gender: Region: Job: Health:

1. Talk about yourself (place of living, work status, where do you spend your time...)

2. Please describe the reasons (educational regulations, economic, social, familial, educational...) that prevent you from going to school?

3. Do you have any idea about other types of education (i.e. Home schooling, Dropout Educating program....)?

4. Other comments or solutions? 


\section{Questions for Dropped out Students}

Age: Gender: Region: Job: Health:

1. Talk about yourself (place of living, work status, where you spend your time...)

2. Please describe the reasons (educational regulations, economic, social, familial, educational...) that encouraged you to drop out from your school?

3. Do you have any idea about other types of education (i.e. Home-schooling Dropout Educating program....)?

4. Other comments or solutions?

Questions for School Age Syrian Refugee Students

1. Talk about yourself (place of living, work status, where you spend your time...)

2. Please describe the reasons that prevent you from going to school?

Points for the interviewer: (educational regulations, economic, social, familial, educational...)

3. Any comment or solutions?

\subsection{ANNEX 2}

Number and distribution of KG sections among governorates and educational authorities, 2015

\begin{tabular}{|c|c|c|c|c|c|c|c|c|c|}
\hline \multirow[t]{2}{*}{ Governorate } & \multicolumn{2}{|c|}{ MoE } & \multicolumn{2}{|c|}{ Private } & \multicolumn{2}{|c|}{ Governmental Non-MoE } & \multicolumn{3}{|c|}{ Total } \\
\hline & $\begin{array}{l}\text { No. of } \\
\text { Students }\end{array}$ & $\begin{array}{c}\text { No. of } \\
\text { Sections }\end{array}$ & $\begin{array}{l}\text { No. of } \\
\text { Students }\end{array}$ & $\begin{array}{l}\text { No. of } \\
\text { Sections }\end{array}$ & $\begin{array}{l}\text { No. of } \\
\text { Students }\end{array}$ & $\begin{array}{l}\text { No. of } \\
\text { Sections }\end{array}$ & $\begin{array}{l}\text { No. of } \\
\text { Students }\end{array}$ & $\begin{array}{l}\text { No. of } \\
\text { Sections }\end{array}$ & $\begin{array}{l}\text { No. of } \\
\text { Teachers }\end{array}$ \\
\hline \multirow[t]{4}{*}{ Irbid } & 1275 & 0 & 8380 & 23 & 0 & 0 & 9655 & 23 & 0 \\
\hline & 1511 & 0 & 7499 & 9 & 0 & 0 & 9010 & 9 & 1080 \\
\hline & 0 & 141 & 0 & 828 & 0 & 0 & 0 & 969 & 0 \\
\hline & 2786 & 141 & 15879 & 860 & 0 & 0 & 18665 & 1001 & 1080 \\
\hline \multirow[t]{4}{*}{ Balqa'a } & 912 & 0 & 3827 & 9 & 0 & 0 & 4739 & 9 & 0 \\
\hline & 975 & 1 & 3328 & 7 & 0 & 0 & 4303 & 8 & 485 \\
\hline & 0 & 93 & 0 & 346 & 0 & 0 & 0 & 439 & 0 \\
\hline & 1887 & 94 & 7155 & 362 & 0 & 0 & 9042 & 456 & 485 \\
\hline \multirow[t]{4}{*}{ Zarqa } & 678 & 1 & 5744 & 44 & 113 & 0 & 6535 & 45 & 0 \\
\hline & 710 & 1 & 5033 & 27 & 105 & 0 & 5848 & 28 & 744 \\
\hline & 0 & 62 & 0 & 561 & 0 & 6 & 0 & 629 & 0 \\
\hline & 1388 & 64 & 10777 & 632 & 218 & 6 & 12383 & 702 & 744 \\
\hline \multirow[t]{4}{*}{ Tafeleh } & 391 & 0 & 812 & 3 & 0 & 0 & 1203 & 3 & 0 \\
\hline & 390 & 0 & 699 & 2 & 0 & 0 & 1089 & 2 & 101 \\
\hline & 0 & 35 & 0 & 65 & 0 & 0 & 0 & 100 & 0 \\
\hline & 781 & 35 & 1511 & 70 & 0 & 0 & 2292 & 105 & 101 \\
\hline \multirow[t]{4}{*}{ Amman } & 1768 & 5 & 20431 & 73 & 0 & 0 & 22199 & 78 & 0 \\
\hline & 1956 & 3 & 18097 & 44 & 0 & 0 & 20053 & 47 & 2962 \\
\hline & 0 & 165 & 0 & 2135 & 0 & 0 & 0 & 2300 & 0 \\
\hline & 3724 & 173 & 38528 & 2252 & 0 & 0 & 42252 & 2425 & 2962 \\
\hline
\end{tabular}




\begin{tabular}{|c|c|c|c|c|c|c|c|c|c|}
\hline \multirow[t]{4}{*}{ Aqaba } & 603 & 1 & 1351 & 0 & 0 & 0 & 1954 & 1 & 0 \\
\hline & 642 & 0 & 1174 & 0 & 0 & 0 & 1816 & 0 & 172 \\
\hline & 0 & 57 & 0 & 106 & 0 & 0 & 0 & 163 & 0 \\
\hline & 1245 & 58 & 2525 & 106 & 0 & 0 & 3770 & 164 & 172 \\
\hline \multirow[t]{4}{*}{ Karak } & 1080 & 4 & 1929 & 7 & 0 & 0 & 3009 & 11 & 0 \\
\hline & 1019 & 1 & 1658 & 0 & 0 & 0 & 2677 & 1 & 305 \\
\hline & 0 & 113 & 0 & 175 & 0 & 0 & 0 & 288 & 0 \\
\hline & 2099 & 118 & 3587 & 182 & 0 & 0 & 5686 & 300 & 305 \\
\hline \multirow[t]{4}{*}{ Mafraq } & 1320 & 1 & 1125 & 1 & 0 & 0 & 2445 & 2 & 1 \\
\hline & 1274 & 1 & 1031 & 4 & 0 & 0 & 2305 & 5 & 245 \\
\hline & 0 & 125 & 0 & 117 & 0 & 0 & 0 & 242 & 0 \\
\hline & 2594 & 127 & 2156 & 122 & 0 & 0 & 4750 & 249 & 246 \\
\hline \multirow[t]{4}{*}{ Jarash } & 572 & 0 & 1286 & 2 & 0 & 0 & 1858 & 2 & 0 \\
\hline & 581 & 0 & 1135 & 1 & 0 & 0 & 1716 & 1 & 191 \\
\hline & 0 & 55 & 0 & 124 & 0 & 0 & 0 & 179 & 0 \\
\hline & 1153 & 55 & 2421 & 127 & 0 & 0 & 3574 & 182 & 191 \\
\hline \multirow[t]{4}{*}{ Ajloun } & 422 & 0 & 861 & 9 & 0 & 0 & 1283 & 9 & 0 \\
\hline & 457 & 0 & 817 & 6 & 0 & 0 & 1274 & 6 & 171 \\
\hline & 0 & 50 & 0 & 93 & 0 & 0 & 0 & 143 & 0 \\
\hline & 879 & 50 & 1678 & 108 & 0 & 0 & 2557 & 158 & 171 \\
\hline \multirow[t]{4}{*}{ Madaba } & 548 & 1 & 1343 & 0 & 0 & 0 & 1891 & 1 & 0 \\
\hline & 550 & 0 & 1128 & 1 & 0 & 0 & 1678 & 1 & 179 \\
\hline & 0 & 52 & 0 & 113 & 0 & 0 & 0 & 165 & 0 \\
\hline & 1098 & 53 & 2471 & 114 & 0 & 0 & 3569 & 167 & 179 \\
\hline \multirow[t]{4}{*}{ Ma'an } & 754 & 2 & 883 & 3 & 0 & 0 & 1637 & 5 & 0 \\
\hline & 767 & 0 & 827 & 1 & 0 & 0 & 1594 & 1 & 188 \\
\hline & 0 & 90 & 0 & 85 & 0 & 0 & 0 & 175 & 0 \\
\hline & 1521 & 92 & 1710 & 89 & 0 & 0 & 3231 & 181 & 188 \\
\hline \multirow[t]{4}{*}{ Grand Total } & 10323 & 15 & 47972 & 174 & 113 & 0 & 58408 & 189 & 1 \\
\hline & 10832 & 7 & 42426 & 102 & 105 & 0 & 53363 & 109 & 682 \\
\hline & 0 & 1038 & 0 & 4748 & 0 & 6 & 0 & 5792 & 0 \\
\hline & 21155 & 1060 & 90398 & 5024 & 218 & 6 & 111771 & 6090 & 6824 \\
\hline
\end{tabular}

